\title{
Are there differences by sex in lung cancer characteristics at diagnosis? - a nationwide study
}

\author{
Alberto Ruano-Ravina ${ }^{1,2,3}$, Mariano Provencio ${ }^{4}$, Virginia Calvo de Juan ${ }^{4}$, Enric Carcereny ${ }^{5}$, Anna Estival ${ }^{5}$, \\ Delvys Rodríguez-Abreu ${ }^{6}$, Gretel Benítez ${ }^{6}$, Rafael López-Castro $^{7}$, Marta Belver $^{7}$, María Guirado-Risueño $^{8}$, \\ Carlos Guirao-Rubio ${ }^{8}$, Ana Blasco ${ }^{9}$, Bartomeu Massutí ${ }^{10}$, Ana Laura Ortega ${ }^{11}$, Manuel Cobo ${ }^{12}$, \\ Joaquín Mosquera-Martínez ${ }^{13}$, Carlos Aguado de la Rosa ${ }^{14}$, Joaquim Bosch-Barrera ${ }^{15,16,17}$, \\ Amparo Sánchez-Gastaldo ${ }^{18}$, Edel del Barco Morillo ${ }^{19}$, Óscar Juan ${ }^{20}$, Manuel Dómine ${ }^{21}$, \\ José Manuel Trigo $^{22}$, Diego Pereiro Corbacho ${ }^{23}$, Juana Oramas ${ }^{24}$
}

${ }^{1}$ Department of Preventive Medicine and Public Health, University of Santiago de Compostela, Santiago de Compostela, Spain; ${ }^{2}$ Consortium for Biomedical Research in Epidemiology \& Public Health (CIBER en Epidemiología and Salud Pública/CIBERESP), Madrid, Spain; ${ }^{3}$ Health Research Institute of Santiago de Compostela (Instituto de Investigación Sanitaria de Santiago de Compostela - IDIS), Santiago de Compostela, Spain; ${ }^{4}$ Department of Oncology, Puerta de Hierro University Hospital, Majadahonda, Madrid, Spain; ${ }^{5}$ Medical Oncology Department, Catalan Institute of Oncology, Badalona- Germans Trias i Pujol Hospital B-ARGO group, Barcelona, Spain; ${ }^{6}$ Hospital Insular de Gran Canaria, Las Palmas de Gran Canaria, Spain; ${ }^{7}$ Servicio de Oncología, Sección de oncología médica, Hospital Clínico Universitario de Valladolid, Valladolid, Spain; ${ }^{8}$ Hospital de Elche, Elche, Spain; ${ }^{9}$ Hospital General de Valencia, Valencia, Spain; ${ }^{10}$ Hospital Universitario General de Alicante, Alicante, Spain; ${ }^{11}$ Servicio de Oncología Médica. Complejo Hospitalario de Jaén, Jaén, Spain; ${ }^{12}$ Unidad de Gestión Clínica Intercentros de Oncología Médica, Hospitales Universitarios Regional y Virgen de la Victoria, IBIMA, Málaga, Spain; ${ }^{13}$ Hospital Universitario de A Coruña, A Coruña, Spain; ${ }^{14}$ Department of Oncology, Clínico San Carlos Hospital, Madrid, Spain; ${ }^{15}$ Girona Biomedical Research Institute (IDIBGI), Girona, Spain; ${ }^{16}$ Department of Medical Sciences, Medical School, University of Girona, Girona, Spain; ${ }^{17}$ Medical Oncology, Catalan Institute of Oncology, Hospital Universitari Dr. Josep Trueta, Girona, Catalonia, Spain; ${ }^{18}$ Department of Oncology, Hospital Virgen del Rocío, Seville, Spain; ${ }^{19}$ Department of Oncology, Hospital de Salamanca, Slamanca, Spain; ${ }^{20}$ Servicio Oncología Médica, Hospital Universitari i Politécnic La Fe, Valencia, Spain; ${ }^{21}$ Hospital Jiménez Díaz, Madrid, Spain; ${ }^{22}$ Servicio de Oncología Médica y Unidad de Fases I, Hospital Universitario Virgen de la Victoria, Málaga, Spain; ${ }^{23}$ Hospital Universitario Álvaro Cunqueiro, Vigo, Spain; ${ }^{24}$ Hospital Universitario de Canarias, Santa Cruz Tenerife, Spain

Contributions: (I) Conception and design: M Provencio, A Ruano-Ravina; (II) Administrative support: M Provencio; (III) Provision of study materials or patients: All authors; (IV) Collection and assembly of data: M Provencio, A Ruano-Ravina; (V) Data analysis and interpretation: All authors; (VI) Manuscript writing: All authors; (VII) Final approval of manuscript: All authors.

Correspondence to: Mariano Provencio. Hospital Universitario Puerta de Hierro, Madrid, Spain. Email: mprovenciop@gmail.com.

Background: Lung cancer causes approximately $25 \%$ of all cancer deaths. Despite its relevance, few studies have analyzed differences by sex at the time of diagnosis in terms of symptoms, stage, age or smoking status. We aim to assess if there are differences between men and women on these characteristics at diagnosis.

Methods: We analyzed the Thoracic Tumour Registry (TTR), sponsored by the Spanish Lung Cancer Group using a case-series design. This is a nationwide registry of lung cancer cases which started recruitment in 2016. For each case included, clinicians fulfilled an electronic record registering demographic data, symptoms, exposure to lung cancer risk factors, and treatment received in detail. We compared men and women using descriptive statistics.

Results: A total of 13,590 participants took part in this study, 25.6\% women. Women were 4 years younger than men (64 vs. 69), and men had smoked more frequently. Adenocarcinoma was the most frequent histological type in both sexes. Stage IV at diagnosis was $50.8 \%$ in women compared to $43.6 \%$ in men. Weight loss/anorexia/asthenia was the most frequent symptom in both sexes and there were no differences in the number of symptoms at diagnosis. There were no relevant differences in the frequency or number of symptoms by sex when non-small cell lung cancer (NSCLC) and small-cell lung cancer (SCLC) were analyzed separately. Smoking status did not appear to cause different lung cancer presentation in men compared to women. 
Conclusions: There seems to be no differences in lung cancer characteristics by sex at the time at diagnosis on stage, specific symptoms or number of symptoms.

Keywords: Lung neoplasms; symptoms; sex; smoking; small cell lung cancer (SCLC)

Submitted Jul 09, 2021. Accepted for publication Sep 16, 2021.

doi: $10.21037 /$ tlcr-21-559

View this article at: https://dx.doi.org/10.21037/tlcr-21-559

\section{Introduction}

Lung cancer is a relevant health problem. It is estimated that in 2020 it will be the second most incident cancer in US men and women (following prostate and breast cancer, respectively) (1), but it will be the most deadly cancer in both sexes, with a number of deaths very close to the numbers of colon and rectum, pancreas and breast cancers combined. In fact, in Europe and also in Spain, lung cancer is the deadliest cancer (2). The number of new lung cancer cases in Spain for 2021 has been estimated in 29,000 (3). The estimated 5 -survival according to SEER data for the period $2010-2016$ is $20.5 \%$ (4). The Concord-3 study estimated this survival for the period 2010-2014 in the range of $10-20 \%$ through pooling data from different world cancer registries (5).

It is unknown if lung cancer risk may differ between men and women, but there are differences regarding the frequency of histological types. Squamous cell carcinoma and small cell carcinoma are more frequent in males while adenocarcinoma is more frequent in females. This difference has been explained by the differences in the consumption of tobacco type between men and women (dark $v s$. blond tobacco consumption has been more frequent in men). One could expect that those histological types more associated with tobacco smoking would be diagnosed in later stages (squamous and small cell carcinomas) (6). Recent studies have suggested that women might be more susceptible compared to men for the same lifetime smoking exposure (7).

Some authors have observed that men were more likely to be diagnosed at a more advanced stage of lung cancer (8), though this result was not statistically significant. In fact, there are no studies formally addressed to compare lung cancer symptoms at diagnosis by sex, and also if potential differences in the number or type of symptoms may exist comparing men and women by stage at diagnosis. This information is also lacking regarding tobacco consumption, where the presence of symptoms may be different between men and women in never-smokers and ex-smokers or current smokers at diagnosis. Having a large series of lung cancer patients diagnosed in different hospitals and in a relatively short period of time would allow to compare these characteristics by sex and provide relevant information on the possible differences at diagnosis of lung cancer patients by sex.

The aim of this study is to compare lung cancer characteristics by sex using the Spanish Thoracic Tumour Registry, with special emphasis in type and number of symptoms at diagnosis, age at diagnosis, and stage. Lung cancer cases will be classified as non-small cell lung cancer (NSCLC) and small cell lung cancer (SCLC).

We present the following article in accordance with the STROBE reporting checklist (available at https://dx.doi. org/10.21037/tlcr-21-559).

\section{Methods}

\section{Design and setting}

The information used corresponds to a National Registry of lung cancer cases from the Thoracic Tumour Registry (TTR), managed by the Spanish Lung Cancer Group (SLCG) (Grupo Español de Cáncer de Pulmón). The SLCG, which is an independent cooperative group made up of more than 500 participants and mainly oncologists, sponsors the registry (9).

The study was opened to all Spanish hospitals; and the first patient was enrolled in August 2016. The design corresponds to a case-series. The recruitment is still ongoing with more than 75 hospitals taking part. For the present study, patients have been recruited from 63 hospitals distributed throughout the country. Some results from this Registry have been recently published (9-11). The Registry was registered in 2016 in the ClinicalTrials.gov database with the code NCT02941458. The study was approved 
by the institutional review board of the Puerta de Hierro University Teaching Hospital (Majadahonda, Madrid) (Protocol identification of approval: PI 148/15). The study was conducted according to principles of the declaration of Helsinki (as revised in 2013). Written informed consent was obtained from all patients before enrolment. We have recently observed that sex and age distribution of the cases contained in the registry is practically the same as that observed for lung cancer cases in the database of the Spanish Cancer Registries (covering up to $30 \%$ of Spanish population) and also with the National Statistics Institute from years 2017 to 2020 (paper submitted). This coincidence between the three information sources reinforces the representativeness of the registry.

To be included, all patients had to present with pathologically confirmed lung cancer, with no age or gender restrictions. Patients were systematically recruited at the participating hospitals by clinicians belonging to the SLCG. If a hospital decides to participate in the registry, all new lung cancer cases are included. Practically all Spanish regions have a hospital taking part in the registry, and approximately $10 \%$ of all lung cancer cases diagnosed in Spain are included in the registry each year.

\section{Data retrieval}

The methodological group of the Spanish Lung Cancer Registry designed specifically an electronic questionnaire to be used by the TTR. The information from all participants was entered through an electronic questionnaire by clinicians. The questionnaire had different sections: (I) demographic data (gender, age, etc.); (II) detailed history of tobacco use; (III) lung cancer characteristics at diagnosis (including a full list of possible symptoms); (IV) all treatments received (with detailed information on each); (V) presence of specific mutations in driver genes at diagnosis; (VI) disease progression; (VII) survival data.

Regarding symptom presentation, the questionnaire included information on the date and presence/absence of the following symptoms at the time of diagnosis: cough; pain; dyspnoea; haemoptysis; weight loss, anorexia or asthenia; superior vena cava syndrome; aphonia, voice alterations or dysarthria. There was additional space for the inclusion of additional symptoms.

\section{Statistical analysis}

All analysis compared lung cancer characteristics by sex.
The presence of different symptoms was performed separately for NSCLC and SCLC, and included type and number of symptoms broken down by stage at diagnosis. We tested the existence of any association by sex using the chi-square test. When the expected frequency was lower than 5 participants, we used the Fischer's exact test. Lastly, we compared the presence of different symptoms by sex but for different categories of smoking status at diagnosis, classified as never smoker (smoked less than 100 cigarettes over his/her lifetime), ex-smoker (stopped smoking more than 1 year before diagnosis), or current smoker (reported smoking during the year before diagnosis). Missing information on any variable was very low. All analyses were performed using the SPSS v24.0 computer software programme. Results were considered statistically significant at $\mathrm{P}<0.05$.

\section{Results}

This study included a total of 13,590 lung cancer patients, $25.6 \%$ of them women. A sample description broken down by sex is shown in Table 1. Median age at diagnosis was 4 years younger for women compared to men (64vs. 69), and never smokers were much more frequent among women $(33.2 \%$ vs. $4.3 \%)$. Men and women presented adenocarcinoma as the most frequent histological type. There were no relevant differences by stage at diagnosis by sex, with the highest difference for stage IV, comprising $50.8 \%$ for women and $43.6 \%$ for men. Symptoms at diagnosis were not different by sex, and the same occurred for the number of symptoms. The most frequent symptom at diagnosis for both sexes was weight loss/anorexia/asthenia (29\%).

For NSCLC, the most frequent symptom in stage I for both sexes was cough (18\% approximately). In case of stage II, it was cough for men (28.3\%) and weight loss/anorexia/ asthenia for women (22.9\%). Cough was the most frequent symptoms for both sexes in stage III, and in stage IV it was weight loss/anorexia/asthenia also for both sexes (35\%). The differences between symptoms by sex across each stage at diagnosis did not reach the $10 \%$. The number of symptoms present at diagnosis was also very similar between sexes across each stage (Table 2).

Regarding SCLC, the most frequent symptom in males with limited stage at diagnosis was cough (37\%) and weight loss/anorexia/asthenia for females (25.9\%). The difference was of a relevant magnitude for cough at limited stage (37\% for men $v$ s. $21.8 \%$ for women), with the other frequencies being very similar. For extended disease, the most frequent 
Table 1 Sample description broken down by sex

\begin{tabular}{|c|c|c|c|}
\hline Variable & Women & Men & Total \\
\hline \multicolumn{4}{|l|}{ Smoking status, n (\%) } \\
\hline Never smoker & 1,155 (33.2) & $439(4.3)$ & $1,594(11.7)$ \\
\hline Ex-smoker & $1,01029.0)$ & $5,324(52.7)$ & $6,334(46.6)$ \\
\hline Unknown & $44(1.3)$ & $102(1.0)$ & $146(1.1)$ \\
\hline \multicolumn{4}{|l|}{ Histological type, n (\%) } \\
\hline Adenocarcinoma & $2,403(69.1)$ & $4,806(47.5)$ & $7,209(53.0)$ \\
\hline Squamous cell carcinoma & $359(10.3)$ & 2,949 (29.2) & $3,308(24.3)$ \\
\hline Other histological types & $210(6.0)$ & $655(6.5)$ & $865(6.4)$ \\
\hline Unknown & $28(0.8)$ & $90(0.9)$ & $118(0.9)$ \\
\hline \multicolumn{4}{|l|}{ Stage at diagnosis, n (\%) } \\
\hline I & $314(9.0)$ & $936(9.3)$ & 1,250 \\
\hline II & $227(6.5)$ & $788(7.8)$ & 1,015 \\
\hline III & $697(20.0)$ & $2,586(25.6)$ & 3,283 \\
\hline IV & $1,769(50.8)$ & $4,411(43.6)$ & 6,180 \\
\hline Small cell limited & $193(5.5)$ & $441(4.4)$ & 634 \\
\hline Dyspnoea & $891(25.6)$ & $2,595(25.7)$ & $3,486(25.7)$ \\
\hline Haemoptysis & $408(11.7)$ & $1,527(15.1)$ & $1,935(14.2)$ \\
\hline Weight loss, anorexia or asthenia & $1,021(29.3)$ & $3,005(29.7)$ & 4,026 (29.6) \\
\hline Superior vena cava syndrome & $15(0.4)$ & $41(0.4)$ & $56(0.4)$ \\
\hline Aphonia or voice alterations & $109(3.1)$ & $335(3.3)$ & 444 (3.3) \\
\hline \multicolumn{4}{|c|}{ Number of symptoms at diagnosis, $\mathrm{n}(\%)$} \\
\hline 0 & $1,236(35.8)$ & $3,613(36.2)$ & $4,849(36.0)$ \\
\hline 1 & $1,359(39.4)$ & $3,729(37.3)$ & $5,088(37.8)$ \\
\hline 2 & $659(19.1)$ & $1,980(19.6)$ & 2,639 (19.6) \\
\hline 3 & $178(5.2)$ & $597(5.9)$ & $775(5.8)$ \\
\hline 4 or more & $20(0.6)$ & $100(1.0)$ & $120(0.9)$ \\
\hline
\end{tabular}




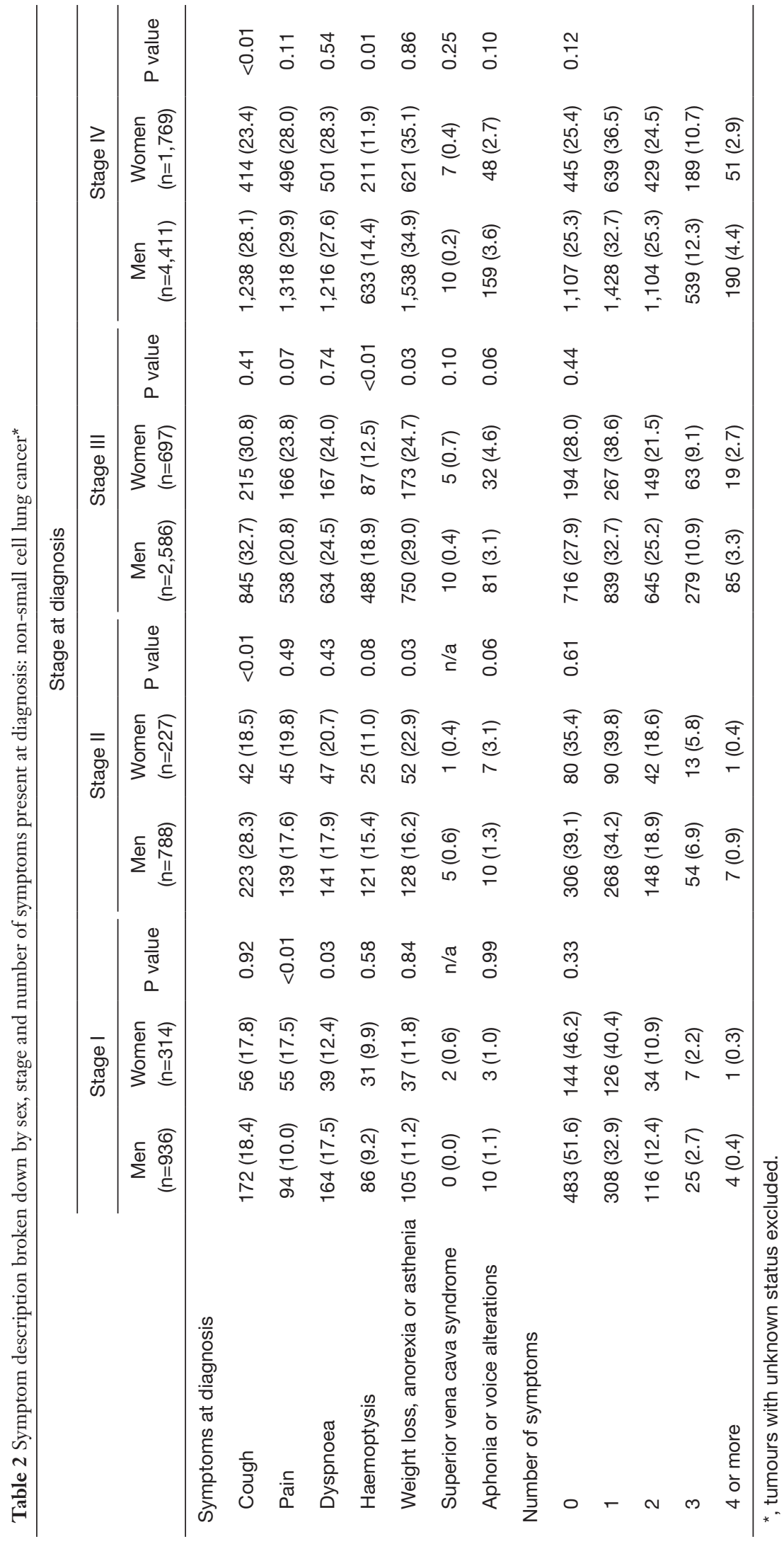


Table 3 Symptom description broken down by sex and stage at diagnosis: small cell lung cancer

\begin{tabular}{|c|c|c|c|c|c|c|c|c|}
\hline Symptoms at diagnoses & \multicolumn{4}{|c|}{ Limited } & \multicolumn{4}{|c|}{ Extended } \\
\hline Cough & & & & $<0.01$ & & & & 0.80 \\
\hline No & $409(67.7)$ & $278(63.0)$ & $151(78.2)$ & & $746(68.9)$ & $593(69.5)$ & $153(66.5)$ & \\
\hline Yes & 205 (32.3) & $163(37.0)$ & $42(21.8)$ & & $337(31.1)$ & $260(30.5)$ & 77 (33.5) & \\
\hline No & 496 (78.2) & $349(79.1)$ & $147(76.2)$ & & $741(68.4)$ & $571(66.9)$ & $170(73.9)$ & \\
\hline Yes & $138(21.8)$ & $92(20.9)$ & $46(23.8)$ & & $342(31.6)$ & $282(33.1)$ & $60(26.1)$ & \\
\hline Dyspnoea & & & & 0.216 & & & & 0.58 \\
\hline No & $450(71.0)$ & $306(69.4)$ & $144(74.6)$ & & $724(66.9)$ & $574(67.3)$ & $150(65.2)$ & \\
\hline Yes & $85(13.4)$ & $65(14.7)$ & $20(10.4)$ & & $148(13.7)$ & $122(14.3)$ & $26(11.3)$ & \\
\hline Weight loss, anorexia or asthenia & & & & 0.92 & & & & 0.07 \\
\hline No & $467(73.7)$ & $324(73.5)$ & $143(74.1)$ & & $668(61.7)$ & $514(60.3)$ & $154(67.0)$ & \\
\hline Yes & $167(23.3)$ & $117(26.5)$ & $50(25.9)$ & & $415(38.3)$ & $339(39.7)$ & $76(33.0)$ & \\
\hline Superior vena cava syndrome & & & & 0.18 & & & & 0.39 \\
\hline No & $616(98.4)$ & $429(98.8)$ & $187(97.4)$ & & $1,050(98.3)$ & $825(98.1)$ & $225(99.1)$ & \\
\hline Yes & $10(1.6)$ & $5(1.2)$ & $5(2.6)$ & & $18(1.7)$ & $16(1.9)$ & $2(0.9)$ & \\
\hline
\end{tabular}

a, chi-square values for each symptom comparing males and females; Fisher exact test when necessary.

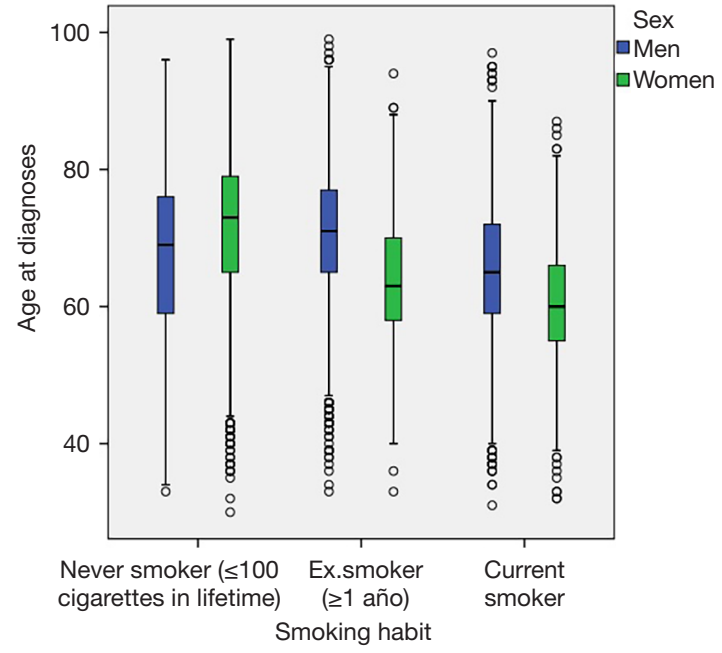

Figure 1 Age at diagnosis broken down by gender and smoking status. symptom for men was weight loss/anorexia/asthenia (39.7\%) and dyspnoea for women (34.8\%). The observed differences for different symptoms in extended disease were not relevant and did not reach 7\% for any of the symptoms compared (Table 3).

Taking into account the age at diagnosis and smoking status by gender, lung cancer was diagnosed earlier in never smoking males compared to females (69 vs. $73 ; \mathrm{P}<0.01$ ). This pattern changed for ex-smokers and current smokers. Median age at diagnosis for ex-smokers was 71 for men compared to 68 for women $(\mathrm{P}<0.01)$; and for active smokers, men had 69 years as the median age at diagnosis compared with 64 for females $(\mathrm{P}<0.01)$. A graphic description of this result is shown in Figure 1.

There were no important differences on the type of symptoms at diagnosis broken down by smoking status 
Table 4 Symptom description broken down by smoking status and tobacco consumption: non-small cell lung cancer

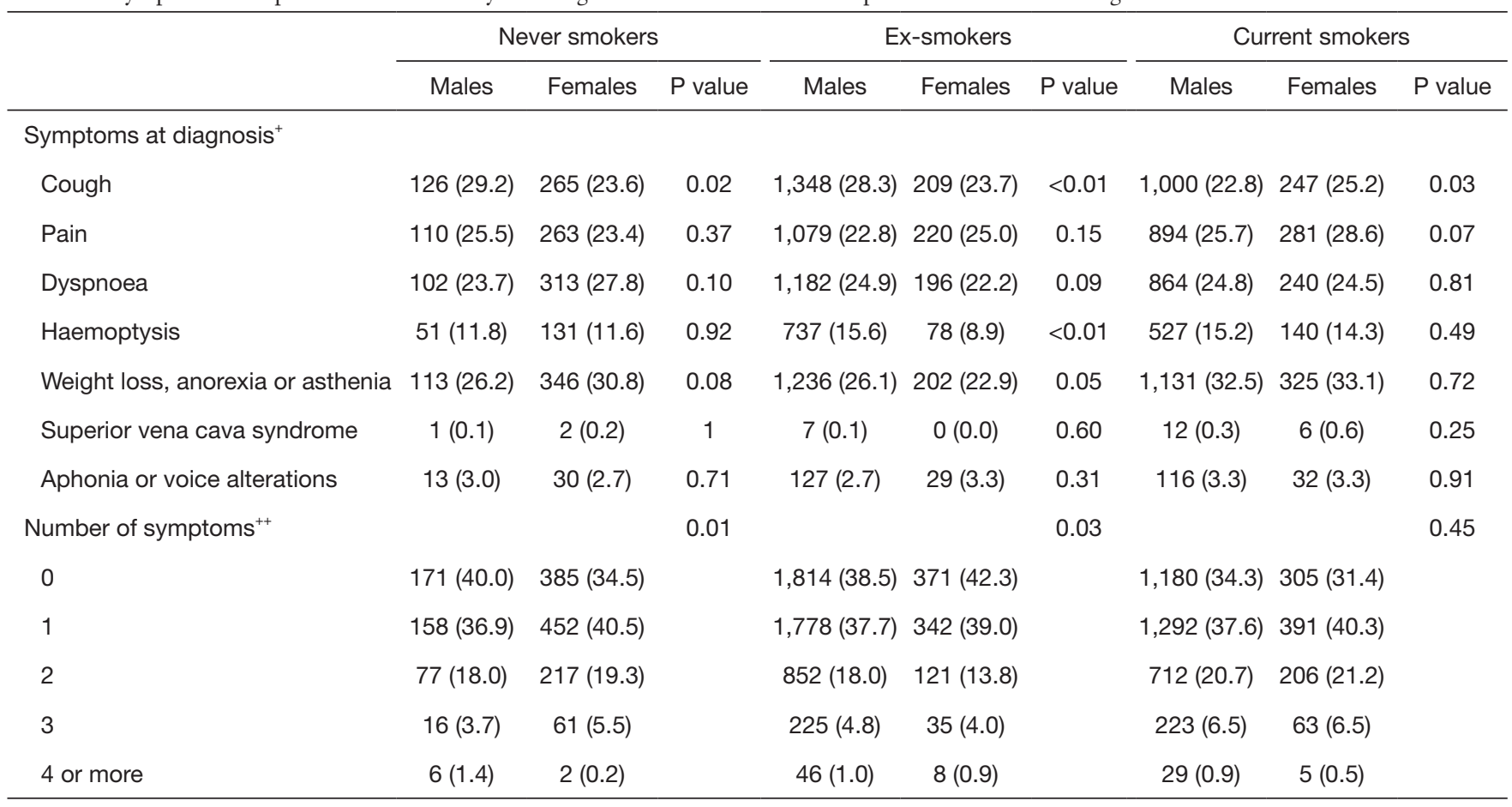

${ }^{+}$, percentages calculated as cases with available information. ${ }^{++}$, totals calculated for each smoking category. Never smoker, participant smoked less than 100 cigarettes in lifetime. Ex-smoker, stopped smoking more than 1 year before diagnosis. Current smoker, declared smoking during the year before diagnosis. 89 participants had unknown tobacco consumption.

and sex in NSCLC. For never smokers, cough was the most frequent symptom among men $(29.2 \%)$ and weight loss/anorexia/asthenia for females (30.8\%). In case of exsmokers, cough was the most frequent symptom among males $(28.3 \%)$ and pain for females $(25 \%)$. For current smokers, weight loss/anorexia/asthenia was the most frequent symptom for males and females $(32.5 \%$ and $33.1 \%)$. The number of symptoms did not increase with smoking status (Table 4). Of note the frequency of cough was practically the same across all smoking categories for women but was less frequent for men who were current smokers (22.8\%) compared to never smokers (29.2\%).

\section{Discussion}

To our knowledge, this is the most comprehensive analysis comparing men and women specifically focused on lung cancer characteristics at diagnosis, including overall symptoms description (type and number), and also the description of these symptoms by stage at diagnoses and smoking status. The main outcome is the lack of differences between men and women on lung cancer symptoms at diagnosis overall and by stage. Of note, it seems that women are diagnosed on average 4 years earlier than men. Other important result is that the number of symptoms do not appear to increase with smoking status, contrary to what we expected, and again that no difference is present by sex and smoking status.

There were no really relevant differences by sex for any of the symptoms assessed by stage in NSCLC and the fact that we have included $25 \%$ of women reflects tobacco epidemics in Spain, where women started smoking much later than men. The most important difference did not reach $10 \%$ and was for cough in stage II, which was present in $28.3 \%$ of males compared to $18.5 \%$ for females. Ten percent of men compared to $17.5 \%$ of women reported pain in stage I patients, and this result was statistically significant. We have not found other studies analyzing this aspect, which should be further explored. The most relevant difference for stage IV was again cough, present in $28.1 \%$ of men compared to $23.4 \%$ of women. We have to highlight that the number of NSCLC females diagnosed with stage I and II was relatively low (314 and 227, respectively). Regarding the number of symptoms present at diagnosis 
by sex and stage it can be observed that there were no differences between men and women. $25.3 \%$ and $24.4 \%$ of men and women, respectively, had no symptoms at diagnosis in stage IV and this figure was $12.3 \%$ and $10.7 \%$ for three symptoms at diagnosis in this stage. The differences for the remaining stages between men and women were very similar. These results suggest that NSCLC has a similar clinical behaviour in both genders, and also point that there is not a predominant symptom in women compared to men for any of the stages at diagnosis.

The pattern of symptoms at diagnosis between men and women is very similar for SCLC compared to NSCLC. The most relevant difference is the presence of cough in limited disease, present in $37 \%$ of men compared to $21.8 \%$ of women $(\mathrm{P}<0.01)$. The differences by sex for other symptoms in limited SCLC did not surpass 6\%. For extended disease, the highest difference is for pain $(33.1 \%$ vs. $26.1 \%$ for males and females, respectively) with the differences for other symptoms being much lower. Of note, the most frequent symptom for extended disease in men was weight loss, anorexia or asthenia (39.7\%) and in women it was dyspnoea, present in $34.8 \%$. A recent paper compared lung cancer symptoms at diagnosis by gender, and the most important difference was for the presence of haemoptysis. Nevertheless, we have to mention that NSCLC and SCLC were not analysed separately and cases were recruited between 1997 and 2011 (12). We have not found any paper comparing symptoms by sex in SCLC.

Age at diagnosis is perhaps one of the most important differences observed by sex, with women being diagnosed 4 years earlier than men. Visbal et al. in a study performed in 4,618 NSCLC patients observed that women were diagnosed two years earlier than men (66 vs. 68) (13). This pattern is the same for ex-smokers and active smokers but never smoking women are diagnosed 4 years later than never smoking men. Other studies have found somewhat different results. A nationwide Estonian study found that men diagnosed in the period 2010-2014 were 2 years younger than women (69 vs. 71) (14). The pattern of age at diagnosis for women is very interesting, since we observe that the higher the tobacco consumption the younger age at diagnosis. Age at diagnosis was very similar to other studies performed in never smokers where exposure to indoor radon was found to be a risk factor of lung cancer (15).

A recent systematic review concluded that women tend to have longer diagnostic intervals but they are usually diagnosed at an earlier stage (16). Nevertheless, this result is not observed in the present study, and it has a higher sample size compared to many of the studies included in that review. In our opinion, there is a general perception that women are diagnosed at an earlier stage compared to men, because they usually have a slightly higher survival, but this is not observed in our results. Some studies have found similar survival rates for both sexes (17), but according to SEER database, 5-year survival for stage $\mathrm{IV}$ is $5.4 \%$ vs. $3.7 \%$ for men and women, respectively (18). Few studies have analysed lung cancer stage at diagnoses by sex, and one of them was published by Visbal et al., who observed minor differences (less than $5 \%$ by stage) (13).

We have also observed small differences between sexes regarding lung cancer symptoms for smokers and neversmokers. This result is very interesting, since some studies observed that women seemed to have a higher lung cancer risk compared to men for the same quantity of tobacco smoked [reviewed in (19)] though controversy still remains. The most relevant difference was for the presence of haemoptysis, which was more frequent in men but only for ex-smokers. The differences observed between symptoms for the different smoking categories were negligible and this was also the case for all the range of the number of symptoms present. We expected a higher number of symptoms for current smokers compared to never-smokers. It is striking the difference observed for the presence of cough in men, which decreased as smoking consumption increased (22.8\% for current smokers and 29.2\% for never smokers). Perhaps this is due because smokers are less aware as cough as a symptom of lung cancer and attribute it to the so-called "smoker cough".

This research has a series of shortcomings. Perhaps the most important is that it was not specifically designed to test the existence of differences on symptoms present at diagnoses, nor to compare these characteristics between different smoking categories. Nevertheless, we are of the opinion that the relevance of the sample size and the consecutive sampling of the participating hospitals overcomes this limitation. A second shortcoming is the fact that for some infrequent characteristics of lung cancer (i.e., early stages or SCLC) we still have a low number of participants to provide fully reliable comparisons. In any case, having included more than 1,000 lung cancer cases in stage II (227 women and 788 men), which is a really infrequent stage at diagnoses, reflects the relative extent of this limitation and the importance of our study. A further limitation is that we do not have accurate information regarding the presence of comorbidities such as COPD, since many patients did not have spirometric information 
on their clinical records to confirm or disregard the real presence of this disease.

This research has a number of advantages. The most relevant is the sample size, the nationwide coverage and the recency of the information provided, which gives a quite clear picture on the true differences between sexes at diagnosis. This updated information, with a very short retrospective component makes easy the extrapolation of these results to other countries, with results that may be included in clinical judgement when there is a suspicion of lung cancer for men and women.

To conclude, these results point out that men and women present similar symptoms at diagnosis of lung cancer and that these symptoms remain essentially the same for NSCLC and SCLC, including their different extent at diagnosis. The number of symptoms is also very similar. There are also no differences by sex regarding different tobacco consumption categories. In our opinion, these results are relevant since they clearly show that the clinical approach to symptom-based lung cancer diagnosis should not be different by sex. These results might be included in awareness campaigns and the thought that men have more or different symptoms at diagnosis than women should be disregarded.

\section{Acknowledgments}

Funding: This research received funding from the Spanish Lung Cancer Group.

\section{Footnote}

Reporting Checklist: The authors have completed the STROBE reporting checklist. Available at https://dx.doi. org/10.21037/tlcr-21-559

Data Sharing Statement: Available at https://dx.doi. org/10.21037/tlcr-21-559

Peer Review File: Available at https://dx.doi.org/10.21037/ tlcr-21-559

Conflicts of Interest: All authors have completed the ICMJE uniform disclosure form (available at https://dx.doi. org/10.21037/tlcr-21-559). MP serves as an unpaid editorial board member of Translational Lung Cancer Research. MP and VCJ receive consulting fees from BMS, ROCHE, ASTRAZENECA, MSD, Boehringer. AE receives consulting fees from ROCHE, MSD, AstraZeneca. GB receives consulting fees from ROCHE, SANOFI. MG receives consulting fees from ROCHE, MSD, Bristol Myers. CAR receives consulting fees from ROCHE, MSD, BMS, AstraZeneca, Novartis, Pierre Fabre. ÓJ receives consulting fees from Boehringer, BMS, Merch, Roche, Astrazeneca, Lilly, Takeda. MD receives consulting fees from Astrazeneca, BMS, Boehriguer, MSD, Pfizer, Roche. JMT receives consulting fees from BMS, MSD, AstraZeneca, Boehringer. The other authors have no conflicts of interest to declare.

Ethical Statement: The authors are accountable for all aspects of the work in ensuring that questions related to the accuracy or integrity of any part of the work are appropriately investigated and resolved. The study was approved by the institutional review board of the Puerta de Hierro University Teaching Hospital (Majadahonda, Madrid) (Protocol identification of approval: PI 148/15). The study was conducted according to principles of the declaration of Helsinki (as revised in 2013). Written informed consent was obtained from all patients before enrolment.

Open Access Statement: This is an Open Access article distributed in accordance with the Creative Commons Attribution-NonCommercial-NoDerivs 4.0 International License (CC BY-NC-ND 4.0), which permits the noncommercial replication and distribution of the article with the strict proviso that no changes or edits are made and the original work is properly cited (including links to both the formal publication through the relevant DOI and the license). See: https://creativecommons.org/licenses/by-nc-nd/4.0/.

\section{References}

1. Siegel RL, Miller KD, Jemal A. Cancer statistics, 2020. CA Cancer J Clin 2020;70:7-30.

2. Sung H, Ferlay J, Siegel RL, et al. Global Cancer Statistics 2020: GLOBOCAN Estimates of Incidence and Mortality Worldwide for 36 Cancers in 185 Countries. CA Cancer J Clin 2021;71:209-49.

3. Red Española de Registros de Cáncer (REDECAN), 2021. Estimaciones de la incidencia del cáncer en España, 2021. [Internet]. Available online: https://redecan.org/redecan. org/es/Informe_incidencia_REDECAN_2021.pdf

4. SEER database, Surveillance, Epidemiology and End Results database. Cancer Stats Facts: Lung and Bronchus 
Cancer. [Internet]. [Accessed 13/10/2019]. Available online: https://seer.cancer.gov/statfacts/html/lungb.html

5. Allemani C, Matsuda T, Di Carlo V, et al. Global surveillance of trends in cancer survival 2000-14 (CONCORD-3): analysis of individual records for 37513025 patients diagnosed with one of 18 cancers from 322 population-based registries in 71 countries. Lancet 2018;391:1023-75.

6. Tolwin Y, Gillis R, Peled N. Gender and lung cancerSEER-based analysis. Ann Epidemiol 2020;46:14-9.

7. Hansen MS, Licaj I, Braaten T, et al. Sex Differences in Risk of Smoking-Associated Lung Cancer: Results From a Cohort of 600,000 Norwegians. Am J Epidemiol 2018;187:971-81.

8. Lyratzopoulos G, Abel GA, Brown CH, et al. Sociodemographic inequalities in stage of cancer diagnosis: evidence from patients with female breast, lung, colon, rectal, prostate, renal, bladder, melanoma, ovarian and endometrial cancer. Ann Oncol 2013;24:843-50.

9. Provencio M, Carcereny E, Rodríguez-Abreu D, et al. Lung cancer in Spain: information from the Thoracic Tumors Registry (TTR study). Transl Lung Cancer Res 2019;8:461-75.

10. Barquín M, Calvo V, García-García F, et al. Sex is a strong prognostic factor in stage IV non-small-cell lung cancer patients and should be considered in survival rate estimation. Cancer Epidemiol 2020;67:101737.

11. Ruano-Raviña A, Provencio M, Calvo de Juan V, et al. Lung cancer symptoms at diagnosis: results of a nationwide

Cite this article as: Ruano-Ravina A, Provencio M, Calvo de Juan V, Carcereny E, Estival A, Rodríguez-Abreu D, Benítez G, López-Castro R, Belver M, Guirado-Risueño M, GuiraoRubio C, Blasco A, Massutí B, Ortega AL, Cobo M, MosqueraMartínez J, Aguado de la Rosa C, Bosch-Barrera J, SánchezGastaldo A, del Barco Morillo E, Juan Ó, Dómine M, Trigo JM, Pereiro Corbacho D, Oramas J. Are there differences by sex in lung cancer characteristics at diagnosis? - a nationwide study. Transl Lung Cancer Res 2021;10(10):3902-3911. doi: $10.21037 /$ tlcr-21-559 registry study. ESMO Open 2020;5:e001021.

12. Athey VL, Walters SJ, Rogers TK. Symptoms at lung cancer diagnosis are associated with major differences in prognosis. Thorax 2018;73:1177-81.

13. Visbal AL, Williams BA, Nichols FC 3rd, et al. Gender differences in non-small-cell lung cancer survival: an analysis of 4,618 patients diagnosed between 1997 and 2002. Ann Thorac Surg 2004;78:209-15; discussion 215.

14. Aareleid T, Zimmermann ML, Baburin A, et al. Divergent trends in lung cancer incidence by gender, age and histological type in Estonia: a nationwide population-based study. BMC Cancer 2017;17:596.

15. Lorenzo-González M, Ruano-Ravina A, Torres-Durán M, et al. Lung cancer and residential radon in never-smokers: A pooling study in the Northwest of Spain. Environ Res 2019;172:713-8.

16. Rana RH, Alam F, Alam K, et al. Gender-specific differences in care-seeking behaviour among lung cancer patients: a systematic review. J Cancer Res Clin Oncol 2020;146:1169-96.

17. Bugge A, Kongerud J, Brunborg C, et al. Gender-specific survival after surgical resection for early stage non-small cell lung cancer. Acta Oncol 2017;56:448-54.

18. SEER database. Surveillance, Epidemiology and End Results program. United States. SEER 18 database. Accessed 13/12/2020.

19. Stapelfeld C, Dammann C, Maser E. Sex-specificity in lung cancer risk. Int J Cancer 2020;146:2376-82. 